\title{
THE
}

\section{DUBLIN JOURNAL OF MEDICAL SCIENCE}

INCLUDING

THE TRANSACTIONS OF THE ROYAL ACADEMY OF MEDICINE IN IRELAND

FOURTH SERIES. No. 8 OCTOBER 1920

\section{ORIGINAL COMMUNICATIONS.}

TWO MEDIASTINAL CASES.

By JOHN SPEARS.

CASE I.-Mr. H., aged sixty-eight, a commercial agent. Date 17th July, 1920. His chief complaint was of a constant pain in his right shoulder. He stated that this pain began in October, 1919, quite sharply, and that he had suffered " night and day ever since." The pain was of an acute character, and did not go down his arm or up his neck. He was a heavilybuilt man-212 lbs. weight-and he acknowledged to a past history of alcohol, but had been a teetotaller for some years. He was married, but had no family. At the time of examination his breathing was of a somewhat jerky character (respirations 21). He had a harsh, short cough, of which he did not complain, usually not productive, but he stated that he had seen some specks of blood about three weeks previously in his sputum. His voice was low- 


\section{DUBLIN JOURNAL OF MEDICAL SCIENCE}

pitched, but not hoarse, and there was no difficulty or pain on swallowing. His hands and face were cyanosed, and the right ear and right side of neck were slightly adematous. The veins on the same side were congested. On further examination the painful area was in the suprascapular region close to the shoulder, localised to about three inches square. There was no local physical signno crepitus in the shoulder joint, and the pain was not increased by moving the arm. The expansion of the right thorax was one inch less than the left, and there was a definite area of dulness from the third to the fifth right ribs, extending from the mid-sternal to the mid-clavicular line. Posteriorly there was an area of dulness not so well defined around the root of the lung. Breath sounds were not well marked over this area anteriorly, and were very indistinct posteriorly. There were a few coarse crepitations in both lungs, and vocal fremitus and vocal resonance were increased slightly. There was no bulging, no pulsation, no tracheal tug, no displacement of liver, the pupils were somewhat unequal. He had a well marked mitral regurgitant murmur, conducted round into the axilla. Apex beat was on the nipple line. Blood-pressure was $150 \mathrm{~mm}$. systolic and $85 \mathrm{~mm}$. diastolic (both arms). Blood examination: Hb. 100 ; count normal ; differential count normal. Urine contained a trace of albumen. A preliminary diagnosis of a mediastinal tumour was made pending $x$-ray report.

First X-ray Report, 19th July, 1920.

"There is a large, dense, irregular-shaped mass of shadow springing from the root of the right lung and extending outwards as far as the lateral wall of the thorax. There was no illumination of this area on deep inspiration. The left lung is normal. The $x$-ray appearance suggests a lymph-sarcoma. There is slight general dilatation of the arch of the aorta, and the heart is slightly enlarged."

It was decided to treat him with $x$-rays. His condition gradually became worse. In a few days he complained of 
occasional pains in his chest, his cough was troublesome, and he became breathless on the least exertion. On the $28 t]_{1}$ his right arm was oedematous, but there was no difference between the radial pulses. On August 3rd both arms and both legs were much swollen. The area of dulness was greatly increased. There was marked inequality of pupils and dilatation of the superficial epigastric veins. Cyanosis was more marked, there were numerous coarse râles and rhonchi in the chest, and he complained of severe spasms of pain. There were indications of a small effusion. His $x$-ray treatment ended on August 5th, when the following report was given :-

Second X-ray Report, 5th August, 1920.

"With the exception of a very small area in the lower part of the lung the whole of the right chest is uniformly opaque. The appearance is such as one sees in cases of large pleural effusions or empyema, except that one would not expect to find any translucent area in the lower portion of the lung field. The change since the first examination is very marked. I have never before seen a malignant growth (if such it is) progress so rapidly."

It was then decided to tap and insert radium, but the patient liad a very severe hremorrhage, and died on August 7th.

Case IT.-Miss B., aged fifty. Date 26th July, 1920. She gave a long history of rleumatism, and complained of severe headache, attacks of giddiness, difficulty in breathing when lying down, and of a feeling of tightness across the chest as if wearing a very tight corset, and a sensation of weight under ler left breast. She had a slight cough, some expectoration, and was very easily fatigued. She stated that she had lad some attacks of vomiting, was constipated, and frequently laad sweating attacks, palpitation, and a peculiar feeling of heat in the soles of her feet, " as if they had been rubbed with menthol." Her chiel worry was sleeplessness and her peculiar tired feeling. On 


\section{DUBLIN JOURNAL OF MEDICAL SCIENCE}

examination, her general nutrition was good, expansion diminished on the right side. On percussion there was a large area of dulness extending from two inches to the right of the sternum to the left nipple line-most marked between the second and fourth ribs on both sides (she complained that the percussion was painful). Auscultation revealed nothing except indistinct breath sounds. Bloodpressure 136 systolic, 110 diastolic (both arms). Blood examination normal; urine, \&c., normal. Deep reflexes were increased. X-ray report as follows :-

"X-ray Examination of the Thorax.-Both lungs are of equal transparency, while neither lung brightens on inspiration, as the expansion is distinctly limited. The edge of the mediastinal shadow at the level of the roots of both lungs is irregular, and the glands are enlarged and quite unusually opaque. I have never seen a similar case presenting a bilateral appearance, but it seems to me to suggest very strongly a malignant tumour involving both lungs, as a similar appearance in one lung only undoubtedly points to this conclusion."

It was decided to give a course of $x$-ray treatment. During August there was practically no change. Her insomnia was difficult to treat, one-quarter grain of morphia only giving two to three hours' rest-paraldehyde proving the most beneficial. She frequently complained that solid food seemed to stick half-way down. On the 31st August she had a very severe attack of vomiting, and complained of intense substernal pain. The left chest was now more resonant, but she felt weaker. She still complained of the same sensations. On September 15 th $x$-ray report was as follows :-

"As compared with the examination of July 27th, the lungs appear to brighten more on inspiration; and though the mediastinal glands are still very opaque they seem less so, and the margins of the mediastinal shadow are more regular. The expansion is less limited than in the previous examination." 
At present she is greatly improved. The feeling of weight and pressure is less, and she feels stronger.

The Wassermann reaction in both these cases was negative.

Mediastinal tumours are usually classified as benign and malignant - the latter being of more frequent occurrence.

(I.) Benign=Fibromata, lipomata, enlarged lymph glands, dermoid cysts, chondromata.

(II.) Malignant (usually primary) = Carcinomata and sarcomata.

In addition to the above, a certain group of pressure symptoms may be produced by Hodgkins's disease, substernal goitre, persistent thymus (most frequent in infancy), aneurysm, gumma, Potts' disease, tuberculosis. Three cases of dermoid cysts have been diagnosed (Mayo and Brown) by the presence of hair, teeth, \&c., in the sputum.

There does not appear to be any differential point between an aneurysm and a tumour in many cases, and diagnosis rests with $x$-ray. Blood-pressure should be estimated in both arms. Hodgkins's disease, with its pluriglandular enlargement, pyrexia, weakness, enlarged spleen, \&c., and possible opportunities of a microscopic section, is readily differentiated.

Lympho-sarcoma has usually metastases. X-ray and a section from an excised gland may clinch the diagnosis. Sarcomata are more common in the anterior mediastinum, possibly carcinomata in the posterior.

Gummata produce few symptoms, and may be excluded by Wassermann reaction, history, \&c.

The symptoms of a mediastinal tumour depend upon its position and size. A tumour in the posterior mediastinum produces pressure symptoms, late physical signs being predominant, whereas symptoms are early if the growth be in the anterior and superior mediastinum. Blair gives the following table (modified by Lemon) of the common pressure symptoms and signs:- 


\section{DUBLIN JOURNAL OF MEDICAL SCIENCE}

Common Symptoms and Signs of Pressure in the Mediastinum.

\begin{tabular}{|c|c|}
\hline 1. Esophagus & $\begin{array}{r}\text { Dysphagia--(a) persistent when due to direct } \\
\text { pressure } \\
\text { (b) transient when dne to irritation } \\
\text { of the recurrent laryngeal nerve }\end{array}$ \\
\hline 2. Trachea & $\begin{array}{l}\text { Brazen cough (gander cough); dyspnea-often } \\
\text { only on exertion ; stridor, with bellows breath- } \\
\text { ing and indrawn manubrium sterni ; bron- } \\
\text { chorrhea; hemoptysis }\end{array}$ \\
\hline $\begin{array}{l}\text { 3. Root of lung and } \\
\text { pleura }\end{array}$ & $\begin{array}{l}\text { Difficult and insufficient aeration like phthisis ; } \\
\text { pulmonary collapse, consolidation or chronic } \\
\text { pneumonia. May vary from time to time } \\
\text { with variation in pressure }\end{array}$ \\
\hline 4. Nerve trunks ... & $\begin{array}{l}\text { Neuralgic type of pain ; paroxysmal and inter- } \\
\text { mittent }\end{array}$ \\
\hline 5. Pulmonary artery & Systolic murmur, dilated right heart \\
\hline 6. Superior vena cava & $\begin{array}{l}\text { Cyanosis-edema of head and neck and upper } \\
\text { extremities. Collaterals do not pulsate as in } \\
\text { cardiac disease }\end{array}$ \\
\hline $\begin{array}{l}\text { 7. Right pulmonary } \\
\text { veins }\end{array}$ & Hydrothorax and collapse of lung \\
\hline 8. Thoracic duct ... & Marasmus \\
\hline 9. Cardiac plexus ... & $\begin{array}{l}\text { Anginal attacks-simulating angina pectoris; } \\
\text { 3rd cervical to 3rd dorsal segmental dis- } \\
\text { tribution. }\end{array}$ \\
\hline $\begin{array}{l}\text { 10. Sympathotic } \\
\text { nerves }\end{array}$ & $\begin{array}{l}\text { Dilated pupils, indicating irritation; contracted } \\
\text { pupils, indicating paralysis ; no loss of reflex, } \\
\text { except in lues; unilateral sweating, flushing } \\
\text { or pallor }\end{array}$ \\
\hline 11. Vagus nerves $\ldots$ & Dyspepsia, nausea, vomiting, dyspnea, hiccough \\
\hline $\begin{array}{l}\text { 12. Recurrent laryn- } \\
\text { geal nerves }\end{array}$ & $\begin{array}{l}\text { Hoarseness, aphonia, spasm, or paralysis of the } \\
\text { left vocal cord-suffocation }\end{array}$ \\
\hline $\begin{array}{l}\text { 13. Right recurrent } \\
\text { laryngeal nerves }\end{array}$ & Right cord paralysis \\
\hline 14. Phrenic nerves ... & $\begin{array}{l}\text { Unilateral paralysis of the diaphragm. Pain } \\
\text { about the neck just above the clavicle }\end{array}$ \\
\hline
\end{tabular}

In the two cases mentioned in this note, the first was considered to be a sarcoma and the second is very doubtful. 